\title{
EXTENSIVE ROOF GREENERY AS A RESPONSE TO HEAT ISLANDS: SOME PROBLEMS
}

\author{
Matej HOLEČKA ${ }^{1}$, Martin JAMNICKÝ ${ }^{1}$, Matúš KRAJČÍK ${ }^{1}$, Roman RABENSEIFER ${ }^{1 *}$
}

\begin{abstract}
Extensive roof greenery is one of the ways to reduce the extent and impact of urban heat islands. A prerequisite is the correct design and operation of both the structural and vegetation part of a roof. If adequate maintenance, especially irrigation of the greenery, cannot be ensured, the use of extensive roof greenery can also be counterproductive. The case study to be presented deals with problems of a flat roof with extensive greenery above an underground garage under Central European climate conditions. Infrequent irrigation leads to extremely high temperatures of the substrate in the summer and makes the purpose of this roof pointless. The contribution analyzes the reason for the failure of the vegetation part of the roof, which was claimed to be maintenance-free, points out fire safety issues, and suggests improvements that might be considered in similar cases. At the present time, which is marked by the climate change crisis, there is great societal pressure to build green roofs. However, if it is not possible to ensure their perfect functionality, it is perhaps better to use classically proven types of roofs, but with greater reflectivity of the top layer surface.
\end{abstract}

\section{Address}

1 Dept. of Building Structures, Faculty of Civil Engineering, Slovak University of Technology in Bratislava, Slovakia

* Corresponding author: roman.rabenseifer@stuba.sk

\section{Key words}

- Extensive greenery,

- Urban heat island,

- Flat roofs,

- Reflection,

- Absorption.

\section{INTRODUCTION}

The notion of "heat islands" describes densely-built areas that are significantly warmer than their mostly rural surroundings (Wurzer G. et al., 2020). An average annual temperature of this kind of area in cities with 1 million citizens can be $1-3^{\circ} \mathrm{C}$ warmer and during the evening hours, even $12^{\circ} \mathrm{C}$ warmer. Heat islands negatively affect people, energy consumption, cooling costs, and environmental pollution; they also indirectly contribute to the production of greenhouse gases and significantly increase the rate of illnesses and heat-related mortality (Wong, K.V., Paddon, A. and Jimenez, A., 2013).

Roof greenery is one of the ways to reduce the extent and impact of urban heat islands. Green roofs are mostly seen as architectural components that can have a positive influence on the quality of life, particularly in urban settlement structures. This positive effect is manifested on the macro level through improving air quality and also reducing the urban heat island effect. It also improves the quality of life in buildings by raising their interior comfort, especially to the floors directly under the roof. The precondition for effectiveness on the macro level is particularly healthy; the vegetation converts carbon dioxide to oxygen, casts a shadow on the flat roof, and moisturizes the surroundings in the summer. In the winter, it particularly has aesthetic and psychological importance. The care and maintenance of the greenery is of paramount importance; however, for larger areas, it may also be quite a costly affair. The maintenance of green roofs may over time exceed the financial plans of small investors, which is then reflected in a gradual decline of the greenery and a counterproductive change of the roof into a dusty surface with negative im- 


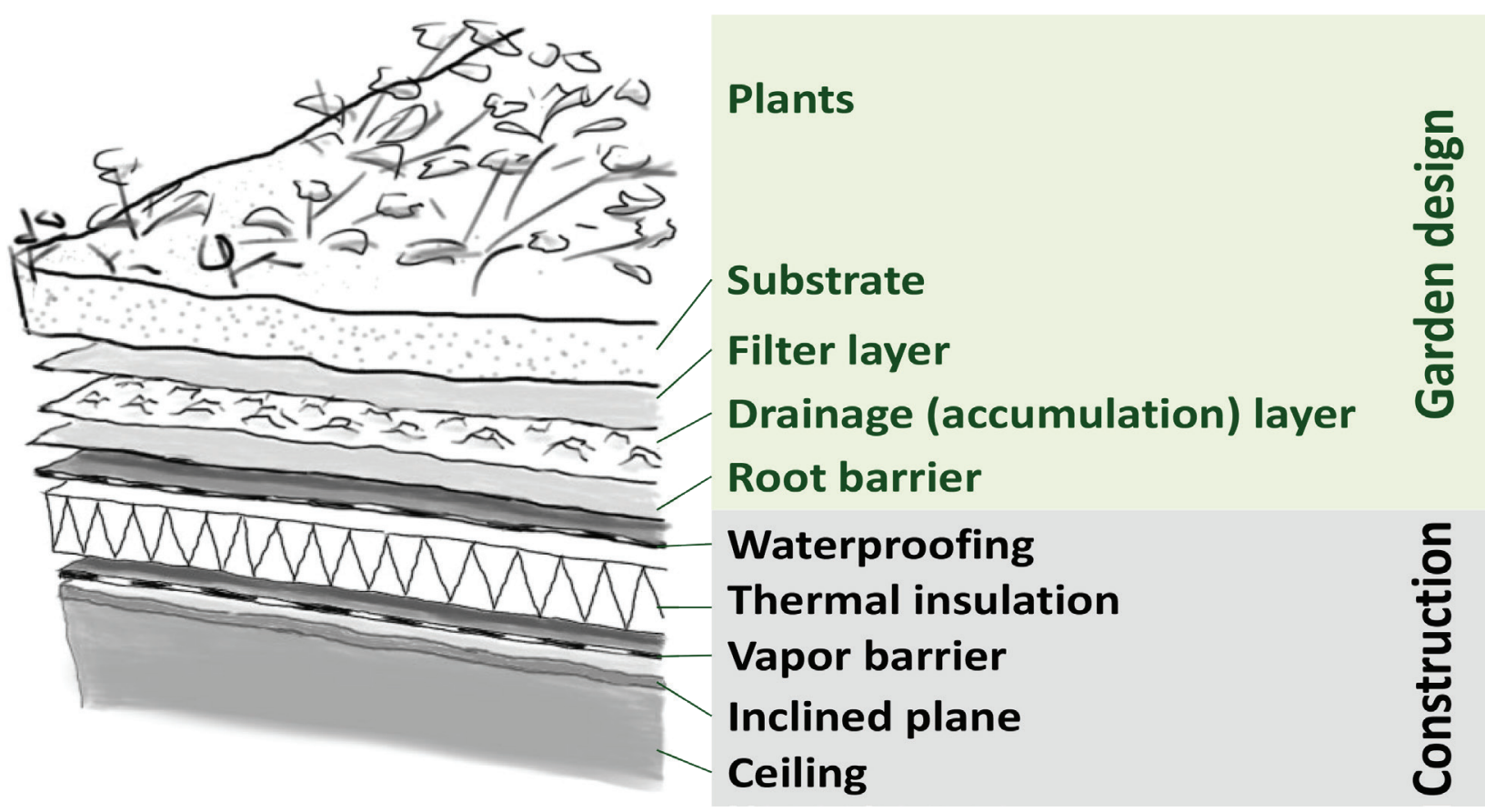

Fig. 1 Layers of a typical vegetation roof (the thickness of the substrate for extensive greenery usually ranges from 6 to $20 \mathrm{~cm}$ )

pacts on the environment. The correct design of greenery reflecting the roof structure and location of the building is therefore very important (see Čermáková, B. and Mužíková, R., 2009).

In terms of the quality of the internal environment, the greenery itself is more or less an insignificant factor; a more important role is played by the substrate, which can contribute to the thermal protection of the internal environment in the summer and the winter as well. In the summer, its ability to absorb solar radiation and thus prevent overheating of the under-roof space is important. In the winter time period, the substrate contributes to the improvement of the thermal resistance of the roof structure, even though it has to be ignored within the calculations of the roof's thermal resistance as it is not an integral part. From a legal point of view, hence, the improved thermal protection of under-roof spaces is a secondary effect of a green roof and, as such, should not play a major role in the decision-making process during the green roof design phase (even though in the case of wooden roofs, it can be quite an important factor). It is more important to consider whether the cost of its construction and operation will provide returns in the form of a more attractive and healthier environment, which is, however, difficult to quantify. The essence of a green roof is greenery and its positive health and aesthetic effects on humans. It can, however, only be achieved if the greenery is truly functional. Under the climatic conditions of Central Europe with approximately four equal seasons, including cold winters; relatively warm, and often dry, summers; plants are grown on a roof with extensive vegetation exposed to extreme temperature fluctuations. This is because green roofs provide an artificial environment similar to large flower pots. Even plants typical of the Central European area that thrive in this environment can have difficulties surviving. If adequate maintenance, especially irrigation of the greenery, cannot be ensured, the use of extensive roof greenery can also be counterproductive. In such a case, it is more appropriate to look at other solutions, e.g., traditional roofs that could be provided with surfaces with a high reflectivity of sunlight. These are much more affordable and can significantly reduce the surface temperature of a roof in the summer.

\section{POTENTIAL OF INCREASING REFLECTIVITY}

Measurements of roof reflectivity in 1992 in Sacramento, California, USA, were done while using aerial photography. These measurements showed the ratio of each individual unit in the city, e.g., $28 \%$ were roofs, $16 \%$ streets, and $14 \%$ parking lots, driveways or pavements. Based on the reflection of these materials, the potential change in reflectivity was estimated to be $18 \%$ (Rodriguez-Droguett, B., 2011). The simplest solution is to change the color of roofs and facades to white. There are several highly reflective materials that are available on the market, e.g., thermoplastic polyolefin-based membranes (TPO) or light gravel for roofs. Pavements and other surfaces can contain white additives (Rodriguez-Droguett, B., 2011). The following case study shows that the most important properties of a green roof in the summer period, i.e., cooling from the evaporation of water and shading by greenery, are lost if the roof is not maintained by regular watering. The dry greenery makes the substrate, which is naturally dark, stand out. The substrate becomes the warmest part of the roof, thereby increasing dust and fire hazards. In such a case, the considerations of a classic flat roof with a reflective top layer would be highly justified.

\section{CASE STUDY}

The aim of the case study was to find out what the temperatures of the different surfaces of a green roof are. Furthermore, we wanted to know the correlation between the temperatures of these surfaces and their estimated reflectivity. Measurements using a Voltcraft infrared thermometer were performed on a green roof above an underground garage in Bratislava (Fig. 2) during peak summer. The reflectivity of the individual materials was estimated on the basis of information from the literature (Decrolux, 2021). The section through the roof layers estimated on the basis of the inspection is in Figures 4 and 5, i.e., part of the greenery. The gravel and terrace part of the roof changed only from the filter 


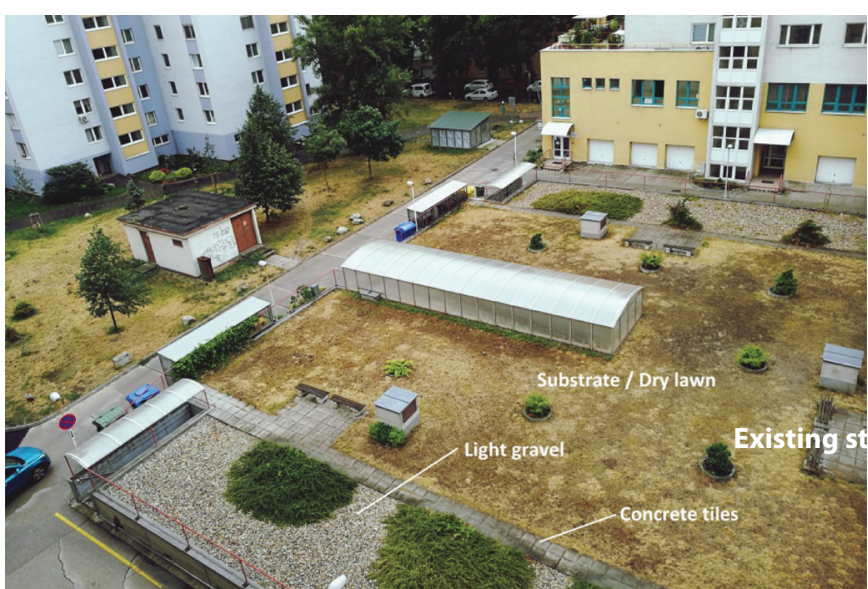

Fig. 2 Top view of the green garage roof

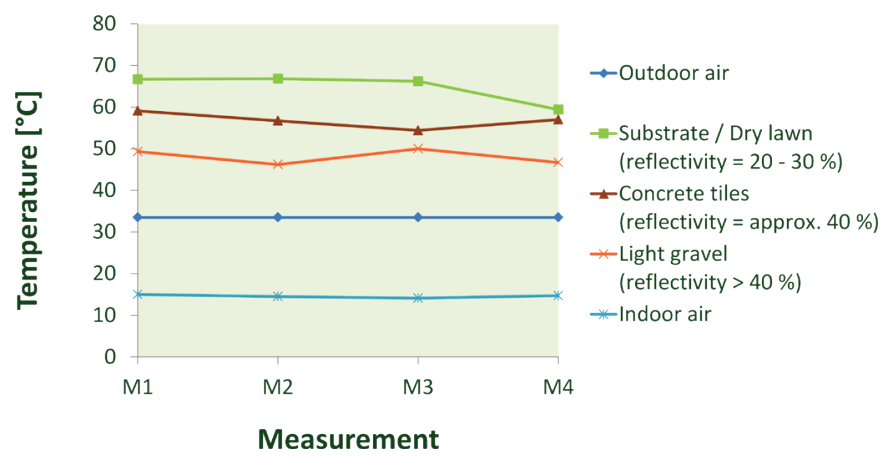

Fig. 3 Temperatures on the garage roof on an early July afternoon, measured using the Voltcraft infrared thermometer; the brackets contain the amount of reflectivity based on the literature sources (Decrolux, 2021); the real value may slightly differ

layer / waterproofing upwards. The gravel finish was self-explanatory. The terrace part consisted of concrete tiles on support pedestals laid on the waterproofing.

The measurements clearly depict the lowest temperatures indoors, which are followed by outdoor air temperatures. As is clearly visible from the measurements (Fig. 3), the temperatures on the substrate / dry lawn were the highest followed by the temperatures measured on the concrete tiles and light gravel. These results support the ideas mentioned in this article, more specifically, the influence of the colors of materials on surface temperatures, since, as is visible in the picture, the flat roof had the highest surface temperatures measured on the substrate/lawn, which is quite the opposite of the desired state.

The roof also shows several commonly known design mistakes such as a non-existing strip of gravel layer around the ventilation shaft from the garage (Fig.4) and the incorrect anchoring of the handrail to the construction (Fig. 5).

In the case depicted in Fig. 5, the vertical wall terminating the roof should be higher, and the railing should be anchored to the side. A protective gravel strip in close proximity to the vertical wall is also missing. It should protect the bend of the waterproofing.

\section{CONCLUSIONS}

In the climatic conditions of Central Europe with four seasons of approximately the same length, including cold winters and rel-
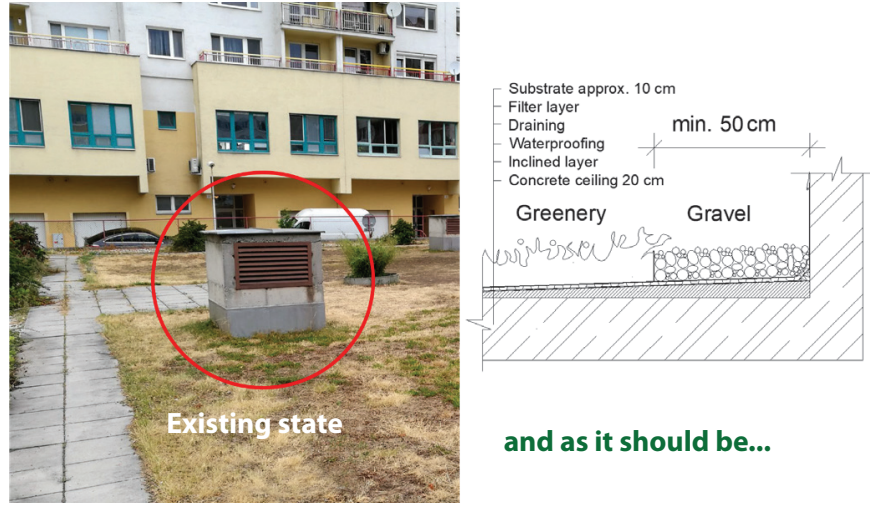

and as it should be...

Fig. 4 Missing strip of gravel layer around the ventilation shaft; the section through the roof layers under the greenery corresponds with the existing state
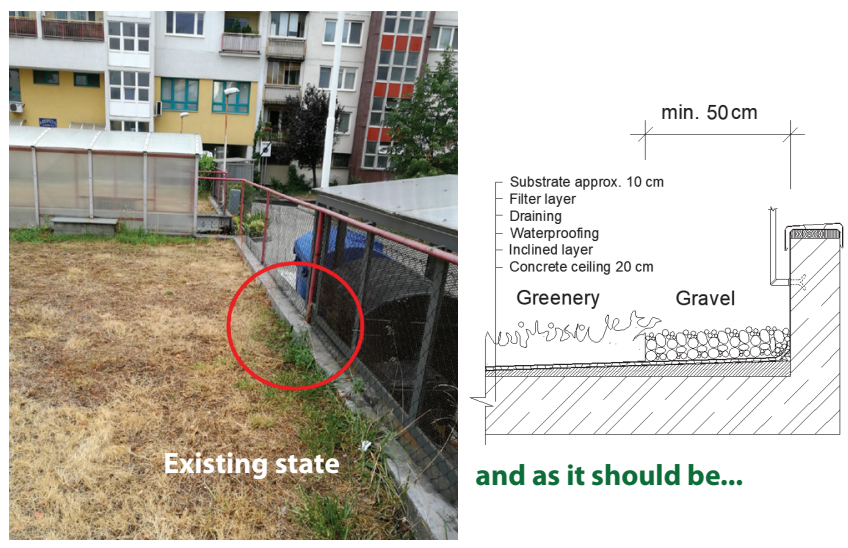

and as it should be...

Fig. 5 Handrail incorrectly anchored to the construction; the section through the roof layers under the greenery corresponds with the existing state

atively warm, and often dry, summers, plants are grown on roofs with extensive vegetation exposed to extreme temperature fluctuations. Even plants typical of the Central European area that thrive in this environment can find it difficult to survive. In contrast to plants rooted in a common soil, the temperature of which oscillates throughout the year at a depth of one meter under the surface between $0^{\circ}$ and approx. $16^{\circ} \mathrm{C}$, i.e., in the range of approx. 16 Kelvin, the roots of vegetation planted on roofs are exposed to a much wider temperature range. From the study of a typical roof with extensive greenery described, it is obvious that temperatures on a roof may be exceedingly high during the peak summer. The selection of suitable plants is therefore extremely important because their root system is exposed to highly contradictory requirements. On the one hand, it must withstand dry periods with high temperatures and, on the other hand, long periods of cold and wetness. When growing more sensitive plants, we also recommend a vegetation layer with a thickness of a few centimeters higher than recommended. The period during which an extensive green roof primarily fulfils its function, i.e., reduces dust and the ambient temperature and oxidizes and humidifies the air, is namely the summer.

Even though extensive vegetated roofs are considered (and promoted) in Central Europe as maintenance- and irrigation-free, they need both year round maintenance and regular irrigation during the summer months. The inclusion of an irrigation system and green maintenance in a roof project is highly desirable, especially with regard to predicted climate change with higher atmospheric temperatures. 
If ensuring the regular maintenance and irrigation of roof greenery is not possible, then a classic flat roof with a highly reflective upper surface is certainly a more suitable solution. Such a roof can reduce the temperature of the roof surface by $10-15$ $\mathrm{K}$ compared to a non-functional substrate and, hence, contribute more to the reduction of the heat island effect.

When planning the details of a green roof, special attention must be paid to fire safety, protection against the growth of roots, and the selection of suitable plants (not simply some kind of succulents). The design of green roofing is a complex matter, which requires a highly professional attitude and strong cooperation between the architect/planner on the one hand and the garden designer on the other hand. Even though there is not too much standardization and legislation regarding roof vegetation, the recommendations of specialized professional associations should be followed.

\section{Acknowledgements}

This article was created with the support of the Erasmus+ program of the European Union within the Hi-Smart Project No. 2019-1-HU01-KA203-060975. The European Commission's support for the production of this article does not constitute an endorsement of the contents, which reflect the views only of the authors, and the Commission cannot be held responsible for any use that may be made of the information contained therein.
Čermáková, B., Mužíková, R. (2009) Ozeleněné střechy (Green Roofs). Published by Grada Publishing, a.s., Prague, CZ, 2009, 246 pp. (in Czech)

Decrolux, Ltd. (2021) Approximate Reflectance Values of Typical Building Finishes, available at: decrolux.com.au (accessed at 19/9/2021) (https://decrolux.com.au/news/2018/approximate-reflectance-values-of-typical-building-finishes)

Oláh, J., Rusnák, R., Urbánek, M. and Žiak, V. (2013) Konštrukcie pozemných stavieb III: Strechy budov (Building Construction III: Roofs of Buildings). Bratislava: Nakladatel'stvo STU (STU Publishing House), 205 pp. (in Slovak)

Rodriguez-Droguett, B. (2011) Sustainability assessment of green infrastructure practices for stormwater management: A comparative emergy analysis. State University of New York College of Environmental Science and Forestry, ProQuest Dissertations Publishing, available at: https://www.proquest.com/ docview/900864997 (accessed at 19/9/2021)
Wong, K.V., Paddon, A., Jimenez, A. (2013) Review of World Urban Heat Islands: Many Linked to Increased Mortality. Journal of Energy Resources Technology, Vol. 135, No. 2, 11 pp., available at the Digital Collection of the American Society of Mechanical Engineers at: https://asmedigitalcollection.asme. org/energyresources/article-abstract/135/2/022101/365904/Review-of-World-Urban-Heat-Islands-Many-Linked-to?redirectedFrom=fulltext (Accessed at 19/9/2021)

Wurzer, G., Pont, U., Lorenz, W.E., Swoboda, S. and Mahdavi, A. (2020) $A$ Web-Based $3 D$ Simulation Platform Aimed at Policy Makers for Estimating the Effects of Urban Heat Islands. Slovak Journal of Civil Engineering, Vol. 28, 2020, No. 2, pp. 18-22. Available under Open Access License at: https://doi.org/10.2478/ sjce-2020-0010 